\title{
QUALITY GRADING OF HEATED RC COLUMNS BY NDT METHODS
}

\author{
Jagath Kumari . Dungi ${ }^{1}$, K. Srinivasa rao ${ }^{2}$ \\ ${ }^{1}$ Assistant Professor, Department of Architecture, School of Planning and Architecture (V), \\ Vijayawada, Andhra Pradesh, India. \\ ${ }^{2}$ Professor, Department of Civil Engineering, College of Engineering, \\ Andhra University, Visakhapatnam, Andhra Pradesh, India. \\ kumari_stru@yahoo.co.in ${ }^{1}$ \\ killamsetti@yahoo.com²
}

\begin{abstract}
Concrete is recognized as a fire-resistant material in construction industry. On the other hand properties of concrete would changes when the concrete exposed to higher temperatures. Several studies has been carried out to investigate the influence of temperature, temperature exposure, exposure duration, and the type of cooling on the residual strength of concrete with various mix grades. In this experimental study, 32 RC column specimens were made. Columns were exposed to fire for temperatures from $100^{\circ} \mathrm{C}$ to $800^{\circ} \mathrm{C}$ with increments of $100^{\circ} \mathrm{C}$ for duration of one hour and two hours. After exposing the columns for specified temperature in electric furnace, they were allowed to cool to room temperature. Out of 32 columns, 16 column specimens were brought to room temperature by air cooling and other 16 columns were brought to room temperature by immediate quenching in water. All the columns were tested identically, for the material integrity by rebound hammer and ultrasonic pulse velocity meter respectively for study. These two tests were carried out on preheating and post heating of the column specimens. The percentage variation of compressive strengths of RCC columns with the increase in temperature has been studied and compared the results. Physical observations of the heated columns were observed. The intention of this experimental work is to investigate the influence of high temperatures of short durations of one hour and two hour (usually period of fires in buildings) on the properties of concrete by nondestructive methods (rebound hammer and ultra pulse velocity) are reported.
\end{abstract}

Key words: Residual compressive strength, rebound hammer no and ultrasonic pulse velocity test.

\section{Introduction}

Through literatures the phenomenon observed with concrete was spalling and cracking when it is exposed to high temperatures. Thermal expansion and dehydration of concrete is due to excessive heating which leads to cracking. This damage in concrete structures due to fire significantly depends on the intensity of fire and duration of exposure. Therefore, the distress in the concrete is obvious in the form of cracking and spalling of the concrete surface. The structures standing decades together cannot be assed the strength by conventional methods. The efficient method of assessment of strength of structure is Non Destructive Testing (NDT), to get in place strength or even for new structure strength. It is an effective tool for damage assessment and quality assurance.

If the building is not totally damaged or it undergo serious damage in one part only, the structural capability of such structures may be quantified by assessing the residual strength of member and material integrity of the concrete. Residual strength of concrete at elevated temperature is defined as the ratio of compressive strength of the heated specimen to that of the unheated specimen.

The residual strengths of heated concrete can be determined by NDT techniques like rebound hammer test and ultrasonic pulse velocity test. These two tests would be performed to express the compressive strength and material integrity.

Fire is extinguished in buildings mostly by using water jetting techniques. In such cases the structures experiences sudden cooling effect while it is in hot condition. If the fire is extinguished by any other technique such as releasing $\mathrm{CO}_{2}$ gas or by throwing buckets of sand the structure will be in hot state which cools down slowly in air. Damage occurs to the concrete structures, in the both post fire conditions which may influence the strength and performance of structure.

Columns in high rise buildings are primary load bearing elements which transfer loads from beams and slabs to the foundation. Hence these members have to meet specified fire resistance ratings in building codes. 


\section{Literature Review}

A lot of research [11-14] on concrete subjected to temperatures was carried out. The researchers exposed the concrete and mortar specimens to normal temperatures and higher temperatures in special furnaces and carried out tests with Non destructive testing of concrete. The object of these investigations was to "determine the strength and deformation properties of concrete at elevated temperatures and to find out the causes of changes that the material suffers in consequence of fire". Some researchers studied the NDT techniques for in place structures and laboratory specimens they mean that, the non-destructive test gives good predicted values for the residual strength.

\section{Experimental Programme}

In this present research, the residual strengths of RCC columns were evaluated at room temperature after exposing them to elevated temperatures from $100^{\circ} \mathrm{Cto} 800^{\circ} \mathrm{C}$ for 1-hour and 2-hours durations of exposure..

\section{A. Materials of concrete mix}

Mix design was done as per IS 10262 -1982 Recommended values of concrete mix design [2].The optimised design mix was achieved for required workability and strength [10]. A laboratory model of column has been prepared as shown in Fig-1.

The concrete mix M20 grade was made in the proportion of 1: 2.01: 3.9 with a water-cement ratio of 0.53 by weight[10]. The cement used was Ordinary Portland Cement (OPC) conforming to IS 8112-1989. The fine aggregate used was natural river sand conforming to zone II of IS 383-1970. The coarse aggregate used was crushed hard blue granite passing through IS $20 \mathrm{~mm}$ sieve and retained on IS $4.75 \mathrm{~mm}$ sieve. Potable water was used.

The reinforced concrete columns are $1200 \mathrm{~mm}$ long and $150 \mathrm{x} 150 \mathrm{~mm}$ in cross-section. All the columns were designed as conforming to IS 456-2000. High Yield Strength Deformed bars (Fe415) conforming to IS 17861985[4] were used as longitudinal reinforcement. Mildsteel bars of $6 \mathrm{~mm}$ diameter are used for lateral ties.
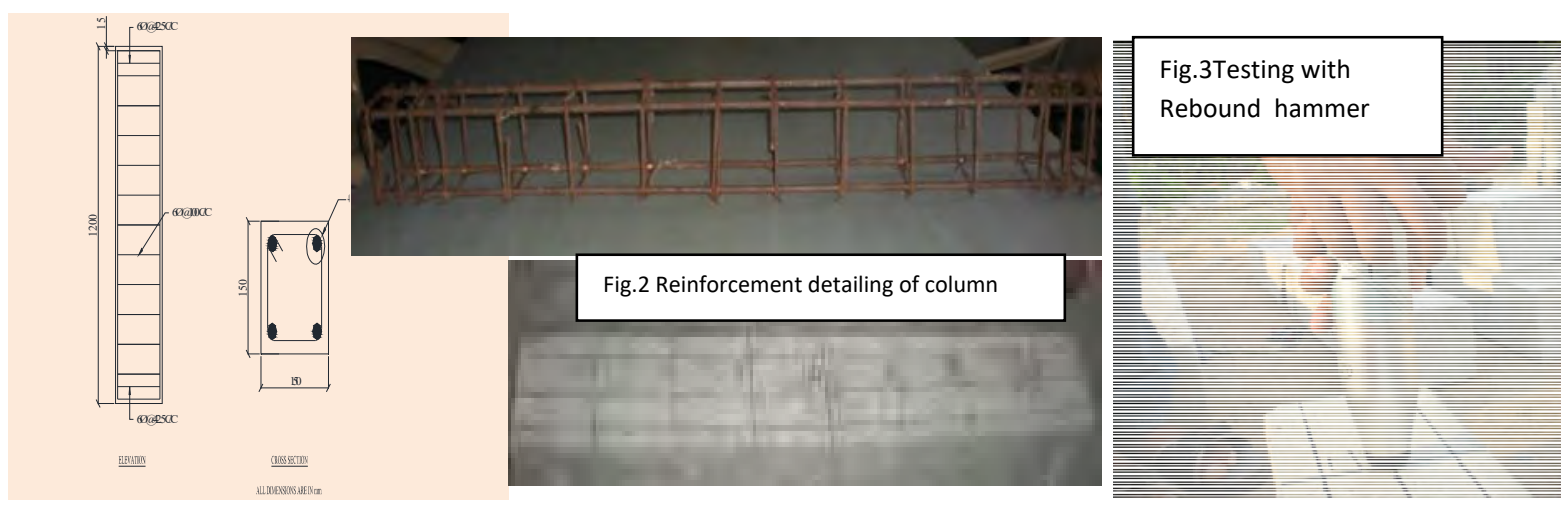

Fig-1 The reinforcement details of Column and testing

\section{B. Casting and curing of Column Specimen}

The columns were casted, each one with a batch of concrete mix. For each batch of mix first the ingredients of concrete are introduced into a laboratory mixer drum. The total mixing was done for 2 minutes. After mixing, the concrete is filled into column moulds in three layers. The compaction has been done with $20 \mathrm{~mm}$ needle vibrator for 45 seconds. The specimen marked and moulds are retained for a period of 24 hours on air drying. Then the specimens were demoulded, as well as cured with fresh water for a period of 28 days in a curing tank.

A total of 32 columns were cast and meant for high temperature exposure. After 28 days of curing, all the column specimens were stored under laboratory air-drying conditions prior to NDT test and for temperature exposure. Each of specimen was tested for compressive strength of concrete and the concrete quality grading using rebound hammer and ultrasonic pulse velocity meter respectively prior to exposure to fire. The testing has been done on two longitudinal side faces of the column by drawing a grid lines at $150 \mathrm{~mm}$ distance along the width on two sides of column, leaving a concrete cover $20 \mathrm{mmon}$ on all sides as shown in fig.1. 


\section{Temperature exposure and testing of specimens}

Total 32 column specimens were exposed to temperatures from $100^{\circ} \mathrm{C}$ to $800^{\circ} \mathrm{C}$ in a furnace in accordance with ISO - 834.Two columns meant for each temperature. The exposure durations are 1-hour and 2-hour at all temperatures. Out of these 32 specimens, 16 specimens each set are exposed to specified durations (for $1 \mathrm{hr}$ and $2 \mathrm{hr}$ ) from which 8 specimens at all durations are natural air cooled and other 8 specimens cooled by immediately quenched in water, which is arranged nearby water tank. After cooling to room temperature again all the columns were tested identically for post fire residual compressive strength of concrete and material integrity that is the quality of concrete in relation to the standard requirements were established with rebound hammer and ultrasonic pulse velocity meter respectively.

\section{Analysis and discussions}

The effect of temperature from 100 to $800^{\circ} \mathrm{C}$ on the strength of M20 grade concrete columns for different duration of exposure ( 1 and 2 hours) and for different cooling methods, using Non destructive testing is studied and critically analyzed in this chapter.

\section{A. Physical changes}

There is no significant colour change for the columns subjected to temperatures below $300^{\circ} \mathrm{C}$. The columns subjected to temperature $300^{\circ} \mathrm{C}$ turned light yellow in colour after cooling them to room temperature by air cooling. From $400^{\circ} \mathrm{C}$ to $600^{\circ} \mathrm{C}$ temperature the specimens turned to lite brown colour. However the columns exposed to temperatures between 700 and $800^{\circ} \mathrm{C}$ became red hot in colour when removed from the furnace and they turned to smoke grey colour after cooling to room temperature.

\section{B. Effect of temperature on probable compressive strength and quality grading}

In this investigation, the effect of temperature on residual strengths has been studied by Rebound hammer test and concrete material integrity by ultra pulse velocity meter (UPV) test has been conducted to understand the behavior of concrete exposed to high temperatures.

Table 1 and Table 2shows that the variation of probable rebound compressive strengths and ultra pulse velocity readings of column specimens after heating from $100-800^{\circ} \mathrm{C}$ respectively.

1) Effect of temperature on probable rebound strength After casting and curing of columns, the rebound hammer test has been performed for each column specimen before heating and after heating to the respective temperatures. The Rebound Hammer test is basically it is surface hardness test and it is used only on concrete surfaces. The Schmidt rebound hammer is simple apparatus and it is extensively used non destructive test device for concrete. The test can be conducted as (in this investigation vertically downwards shown in Fig.3

Table I

\begin{tabular}{|c|c|c|c|c|}
\hline \multirow{2}{*}{ Temperature in ${ }^{\circ} \mathrm{C}$} & \multicolumn{3}{|c|}{ \% Probable compressive strengths by rebound hammer } \\
\cline { 2 - 5 } & \multicolumn{2}{|c|}{ Air Cooling } & \multicolumn{2}{c|}{ Water quenching } \\
\cline { 2 - 5 } & $1 \mathrm{~h}$ & $2 \mathrm{~h}$ & $1 \mathrm{~h}$ & $2 \mathrm{~h}$ \\
\hline 27 & 100 & 100 & 100 & 100 \\
\hline 100 & 100 & 99 & 92 & 88 \\
\hline 200 & 118 & 103 & 99 & 81 \\
\hline 300 & 109 & 100 & 100 & 78 \\
\hline 400 & 102 & 95 & 88 & 74 \\
\hline 500 & 96 & 83 & 84 & 71 \\
\hline 600 & 93 & 90 & 77 & 57 \\
\hline 700 & 90 & 82 & 62 & 50 \\
\hline 800 & 71 & 77 & 49 & 36 \\
\hline
\end{tabular}




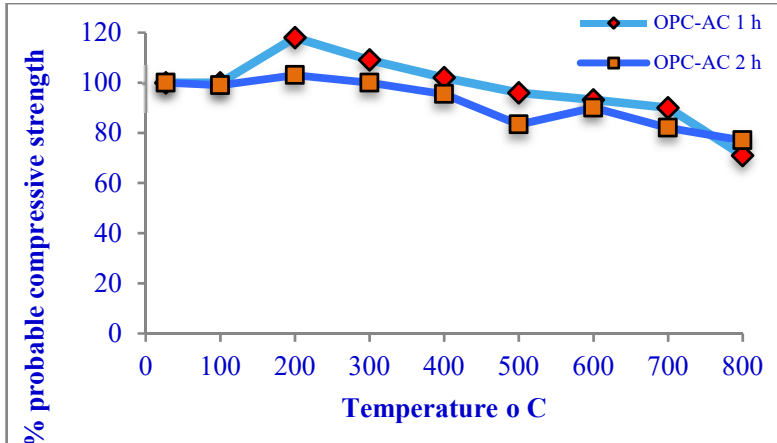

Fig. $5 \%$ variation of probable compressive strength with temperature-OPC concrete air cooling(AC)

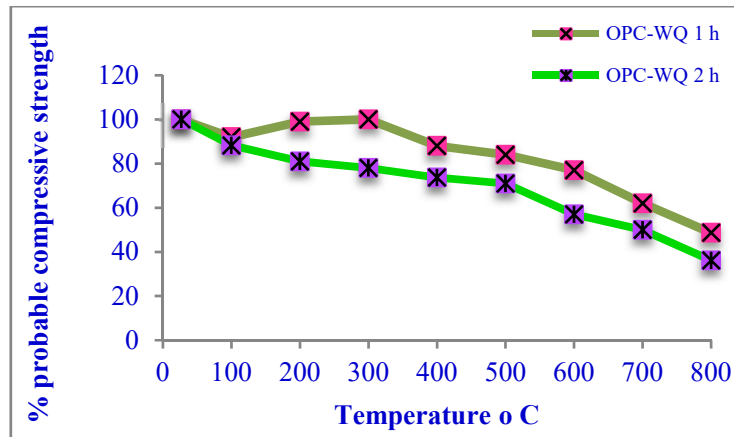

Fig. $6 \%$ variation of probable compressive strength with temperature-OPC concrete water quenching (WQ)

The heating temperatures were 100 to $800^{\circ} \mathrm{C}$ at an interval of $100^{\circ} \mathrm{C}$ and the cooling methods adopted were air cooling and water quenching. Residual properties such as probable compressive strength and UPV are presented. The rebound hammer test results show that the columns retained more than $50 \%$ of individual specimen strengths at all temperatures. The residual strength retained by columns exposed up to $400^{\circ} \mathrm{C}$ for 1 hour and 2 hour durations are relatively similar to strength carried by the column at room temperature for air cooling method specimens. However beyond $400^{\circ} \mathrm{C}$ the columns exposed to 2 hour duration retained slightly less residual strength than the lhour duration of exposure specimens. This has been observed for both methods of cooling of columns. Bulk loss of strength is happening in first 1hour duration of exposure for both methods of cooling. Also the material integrity of the RC columns is reduced for 2 hour exposure duration than the 1 hour exposure. This may be due to the evaporation of free water from 1hour duration to 2 hour duration of exposure of temperatures. The evaporation of pore water reduces the strength and quality grading of concrete, beyond $500^{\circ} \mathrm{C}$ temperature exposure.

2) Effect of temperature on Material Integrity of columns (UPV) of columns: Table no-2 shows that the variation of ultra pulse velocity of the test specimens after heating. The average pulse velocity of all the specimens before heating is $4.3 \mathrm{Km} / \mathrm{sec}$. The result shows that pulse velocity decreased substantially with the increase of high temperatures.

Table II

\begin{tabular}{|c|c|c|c|c|}
\hline \multirow{2}{*}{ Temperature in ${ }^{0} \mathrm{C}$} & \multicolumn{4}{|c|}{ Ultra Pulse Velocities (UPV) Km/sec } \\
\cline { 2 - 5 } & \multicolumn{2}{|c|}{ Air Cooling } & \multicolumn{2}{c|}{ Water quenching } \\
\hline & 1 - hour & 2-hour & 1- hour & 2-hour \\
\hline 27 & 4.3 & 4.3 & 4.3 & 4.3 \\
\hline 100 & 4.2 & 4.2 & 4.1 & 4.1 \\
\hline 200 & 3.7 & 3.7 & 4.1 & 3.7 \\
\hline 300 & 3.9 & 3.9 & 3.7 & 3.5 \\
\hline 400 & 3.7 & 3.1 & 3.3 & 3.2 \\
\hline 500 & 2.9 & 1.9 & 3.0 & 2.9 \\
\hline 600 & 2.4 & 1.6 & 2.8 & 2.4 \\
\hline 700 & 1.2 & 1.3 & 2.4 & 2.2 \\
\hline 800 & 1.3 & 1.0 & 2.1 & 1.6 \\
\hline
\end{tabular}




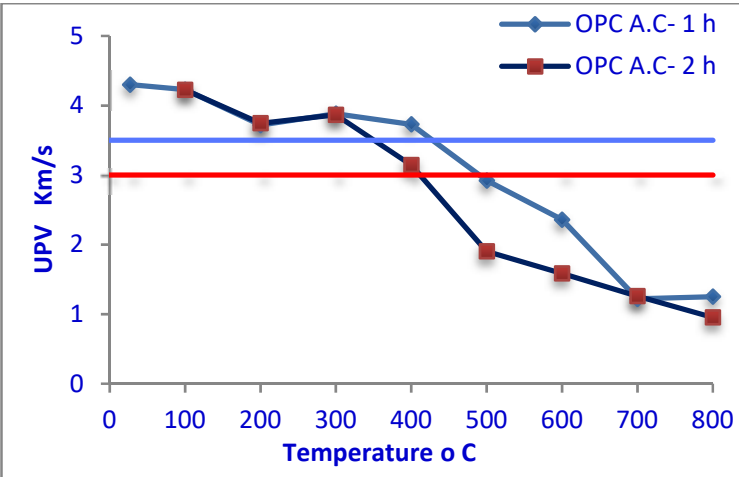

Fig. 7 Variation of UPV with temperature-OPC concrete- air cooling (AC)

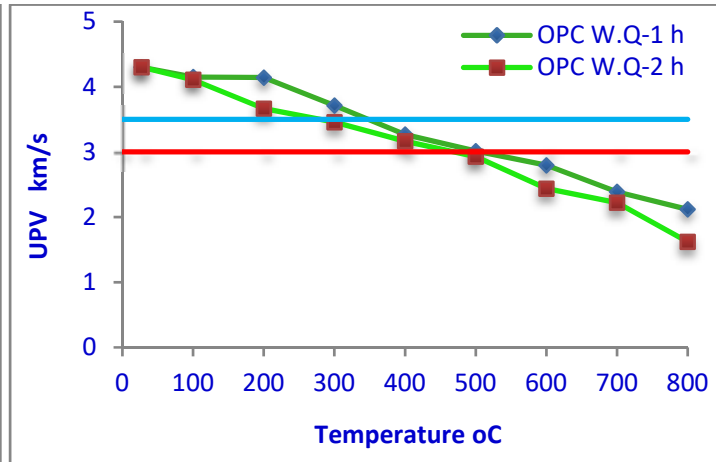

Fig. 8 Variton of UPV with temperature -OPC concrete water quenching- (WQ)

The UPV results show that the concrete quality grading up to $300^{\circ} \mathrm{C}$ is good quality. Beyond $300^{\circ} \mathrm{Cup}$ to $500^{\circ} \mathrm{C}$ the quality grading is moderate and beyond $500^{\circ} \mathrm{C}$ temperature the quality of concrete is poor and it requires further tests according to table -2of IS 13311 part 1-1992 [11]. While observing the readings in table-1, it is clear that up to $600^{\circ} \mathrm{C}$ the rebound compressive strengths are fair; which is indicative that the material integrity in terms of uniformity, incidence or absence of internal flaws, cracks or segregation, etc may be suspected due to increase in temperature exposure. The loss of strength related with the increase in temperature could be a result of loss of moisture driven off during heating to high temperatures. The degradation of the residual strength could be due to combined effect of concrete compressive strength and steel strength reduction. On evaluating two methods of cooling, air cooling specimens retained more strength than water quenching method specimens. The researcher RV Balendran was observed similar findings.

C. Correlation between compressive strength and UPV: The test results show that UPV is comparable to the compressive strength by rebound hammer test results at all temperatures. The correlation between $\%$ compressive strength and \% UPV along with temperature variation is presented below.

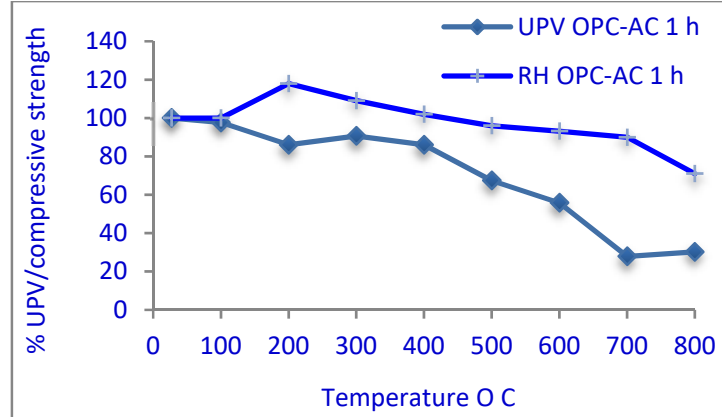

Fig. 9 correlation between UPV- compressive strength - OPC concrete- air cooling(AC)- $1 \mathrm{~h}$

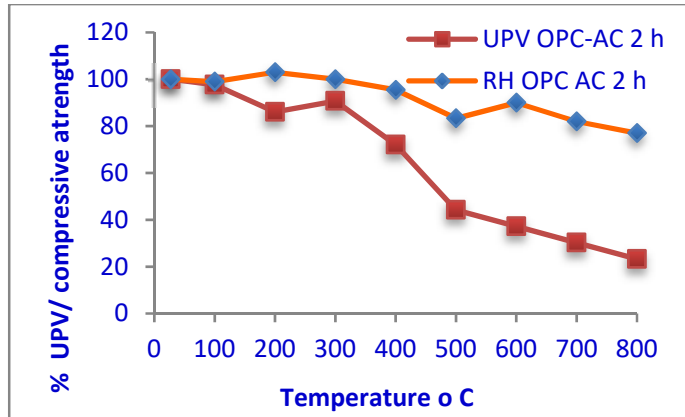

Fig. 10 Correlation between UPV-compressive strength OPC concrte- air cooling (AC)- $2 \mathrm{~h}$

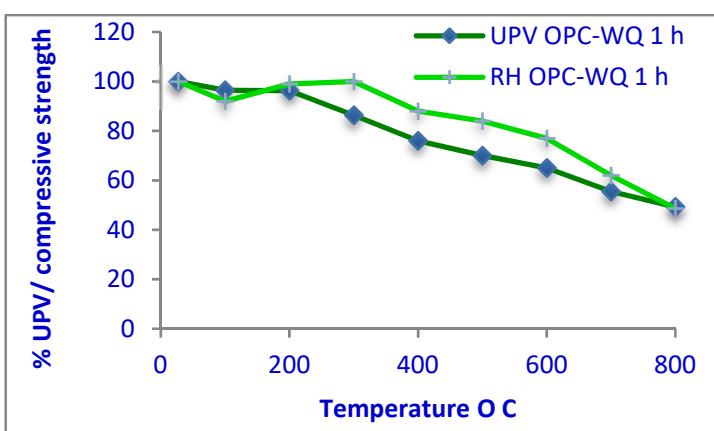

Fig. 11 Correlation between UPV-compressive strength-OPC concrete -water quenching(WQ)- 1

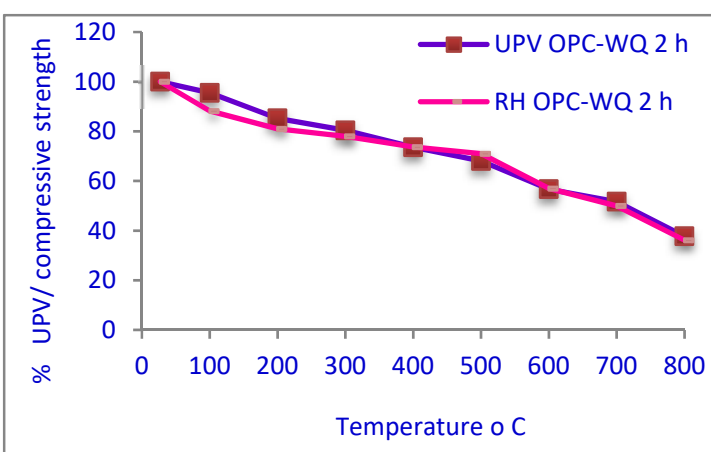

Fig. 12 Correlation between UPV-Compressive strength- OPC concrete-waterquenching(WQ)-2 h 
Fig. 9,10,11,12 shows a considerable relationship between the \% residual compressive strength and the \% residual UPV. A deterioration of concrete on increase in temperature has been observed, from the correlation graphs UPV and compressive strength. The temperature reached by the concrete has a clear and straight forward influence on the ultrasonic pulse velocity and on concrete compressive strength up to $800^{\circ} \mathrm{C}$. The general evolution of the ultrasonic pulse velocity and probable compressive strength with the temperature is comparable for both methods of cooling. The UPV is found to deteriorate at a faster rate with the increase in exposure temperature as compared to the compressive strength. Both the $\%$ residual strength as well as the \% residual UPV decrease with the increase in the exposure temperature for both the cooling methods. However, the variation of \% UPV is more as compared to the variation in \% residual compressive strength. This is because of large amount of cracking that has occurred as a result of high temperature exposure. Concrete experienced higher deterioration of UPV in terms of quality grading rather than strength, when it is cooled by air cooling method for both 1 hour and 2 hour durations of exposure. As the rebound hammer test is surface hardness test the concrete carried considerable amount of strength upto $600^{\circ} \mathrm{C}$. The concrete carried better residual strength by air cooling method than water quenching residual strength.

\section{Conclusions}

The following conclusions have been drawn from this investigation.

1. The M20 grade concrete used for the column specimens maintained its structural integrity $700^{\circ} \mathrm{C}$ by physical observation. At $800^{\circ} \mathrm{C}$ cracks were observed on the surface of the columns.

up to

2. The compressive strengths of all heated columns were lower than the respective un- heated specimens.

3. The Concrete quality grading up to $400^{\circ} \mathrm{C}$ is considerable for $\mathrm{M} 20$ concrete .

4. Beyond $400^{\circ} \mathrm{C}$ temperature, the concrete necessary to carry out further NDT test.

5. Rebound hammer test illustrate the residual strengths of all RC columns are above $50 \%$ of its pre heat individual strengths, up to $700^{\circ} \mathrm{C}$ temperature exposure.

6. The residual strength of columns exposed up to $400^{\circ} \mathrm{C}$ temperatures and brought to room temperature by air cooling carried more strengths than the columns cooled by water quenching. Beyond $400^{\circ} \mathrm{C}$ the water quenching method columns performed better in material integrity by UPV.

7. Bulk loss of strength was observed beyond $400^{\circ} \mathrm{C}$ temperatures within 1 hour duration of exposure for water quenching method of cooling.

\section{References}

[1] Bureau of Indian Standards. Recommend Guidelines for Concrete Mix Design. Bureau of Indian Standards, New Delhi, India, IS: 10262-2009.

[2] Bureau of Indian Standards Indian Standards: Plain and Reinforced Concrete; - Code of Practice (Fourth revision). Bureau of Indian Standards, New Delhi, India, IS: 456-2000.

[3] Bureau of Indian Standards. Specifications for Coarse and Fine Aggregates from Natural Sources for Concrete. Bureau of Indian Standards, New Delhi, India, IS: 383-1970.

[4] Bureau of Indian Standards. Specifications for Admixtures for Concrete. Bureau of Indian Standards, New Delhi, India, IS: 91031999.

[5] Bureau of Indian Standards. Specifications for Portland Pozzolana Cement. Bureau of Indian Standards, New Delhi, India, IS: 14891987.

[6] Bureau of Indian Standards. National Building Code of India. Bureau of Indian Standards, New Delhi, India, NBC - 1970 (Part IV).

[7] Izabela Hager, Hélène Carré , Katarzyna Krzemień "Damage assessment of concrete subjected to high temperature by means of the ultrasonic pulse velocity-upv method" Graduate School in Concrete Structures - Fratelli Pesenti Politecnico di Milano, Italy.

[8] J.C. Agunwamba, T. Adagba "A comparative analysis of the rebound hammer and ultrasonic Pulse velocity in testing concrete" Nigerian journal of technology vol 31, March, 2012, pp.31-39.

[9] D.K.Kulkarni. Mr. Teke Sudhakar. S. Health Assessment Of Reinforced Concrete Structures - A Case Study IOSR Journal of Mechanical \& Civil Engineering (IOSR-JMCE) ISSN: 2278-1684, PP: 37-42

[10] Jagath Kumari.Dungi, K.Srinivasa Rao "Optimizing the cement content in HVFA concrete for Durability and Sustainability "International Journal of Chemical, Environmental \& Biological Sciences (IJCEBS) Volume 1, Issue 4 (2013) ISSN 2320-4079; EISSN 2320-4087

[11] Zoubir Mehdi Sbarta, Stéphane Laurens et al. Concrete properties evaluation by statistical fusion of NDT techniques hal-00756953 version 1-24 November 2012

[12] Hsuanchih YANG 1, Yiching LIN 1, Chiamen HSIAO 2, Yu-Feng LIN 3 Using ultrasonic pulse velocity to evaluate residual compressive strength ofpost-fire-curing concrete 17th World Conference on Non destructive Testing, 25-28 Oct 2008, Shanghai, China

[13] Asst. Lect. Sawsan Akram Hassan Effect of High Elevated Temperatures on the Compressive Strength and Ultrasonic Pulse Velocity of High Strength Concrete Journal of Engineering and Development, Vol. 11, No. 1, March (2007)

[14] Poon CS, Azhar S, Anson M,Wong YL. Strength and durability recovery of fire-damage Concrete after post-fire-curing. Cement and Concrete Research. 2001; 31:1307- 


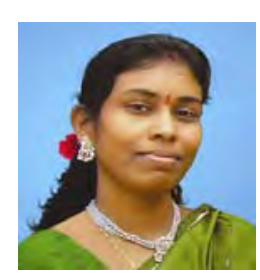

\section{Author Profile}

\section{Name: D. JagathKumari}

Qualifications: B.E. (Civil Engineering), M.E. (SE \& NDM)

D. JagathKumariis currently working as Assistant Professor in the department of Architecture, School of planning and Architecture, Vijayawada. Her research interests includes load carrying capacity of high volume fly ash concrete columns and behaviour of R.C. columns subjected to high temperatures, Non distructive testing and repair, rehabiltation and restoration of structures.

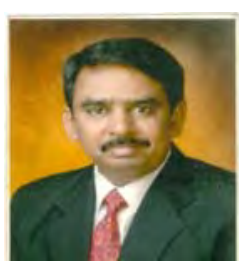

Name:Prof. K. SrinivasaRao

Qualifications: B.E. (Civil Engineering), M.E. (Structural Engineering), Ph.D. (Structures)

Dr.K.SrinivasaRao is currently working as Professor in the Department of Civil Engineering, Andhra University College of Engineering (A), Andhra University, Visakhapatnam. He has about 26 years of teaching experience. He mentored $11 \mathrm{PhD}$ degree holders and $73 \mathrm{M}$. Tech degree holders. His research interests include behaviour of concrete and RCC elements at elevated temperatures, ultra-high strength concrete, geo-polymer concrete, alkali activated slag concrete, Non-Destructive Evaluation of structures, Repair and Rehabilitation of Structures and Earthquake Engineering. He has published about 92 Technical Papers in National \& International Journals and Conferences. 